\title{
Tracer flux balance at an urban canyon intersection
}

\author{
Matteo Carpentieri Alan G. Robins \\ Boundary-Layer Meteorology 135 (2), 229-242 [2010] \\ doi: $10.1007 / \mathrm{s} 10546-010-9471-6$
}

\begin{abstract}
Despite their importance for pollutant dispersion in urban areas, the special features of dispersion at street intersections are rarely taken into account by operational air quality models. Several previous studies have demonstrated the complex flow patterns that occur at street intersections, even with simple geometry. This study presents results from wind tunnel experiments on a reduced scale model of a complex but realistic urban intersection, located in central London. Tracer concentration measurements were used to derive threedimensional maps of the concentration field within the intersection. In combination with a previous study (Carpentieri et al., Boundary-Layer Meteorol. 133:277-296) where the velocity field was measured in the same model, a methodology for the calculation of the mean tracer flux balance at the intersection was developed and applied. The calculation highlighted several limitations of current state-of-the-art canyon dispersion models, arising mainly from the complex geometry of the intersection. Despite its limitations, the proposed methodology could be further developed in order to derive, assess and implement street intersection dispersion models for complex urban areas.
\end{abstract}

\section{Introduction}

The causes of poor air quality in most cities around the world can be found in the results of human activities. World population has more than doubled during the last 50 years, while the number of cars has increased by a factor of 10 . Urban population has increased by a factor of 4 in the same period and this development is expected to continue in the coming years (Fenger. 1999). Most of the harmful pollutants found in cities ( $\mathrm{CO}, \mathrm{NO}_{X}$, volatile organic compounds, particulates, etc.) are emitted by industrial operations (mainly by combustion processes) and traffic. The increase in traffic volume within the densely built and poorly ventilated urban areas is a worrying trend, exacerbated because of the increased numbers who live and work in cities. Human exposure to hazardous substances is expected to increase world-wide, primarily in those areas where population and traffic density are relatively high. Understanding flow and dispersion in urban streets is therefore of paramount importance for air quality management and planning, particularly for reasons related to human health. Furthermore, the particular present international political situation adds further concerns, as the deliberate discharge of toxic material in populated areas is a serious threat.

The sources and dispersion of pollution and its effects on buildings and the population have been the subject of numerous previous studies. Models of varying complexity have been developed and experimental data from the field and wind tunnels use in their validation. Most of 
the work has focussed on simple geometries, such as the well-known urban street canyon (see the reviews of Vardoulakis et al., 2003; Berkowicz et al., 1997; Britter and Hanna, 2003); nevertheless, those attempts to study real urban situations have produced some important insight into the dispersion process, highlighting the role of three-dimensional effects, particularly at street intersections (Soulhac, 2000; Scaperdas, 2000). Pollution hotspots may be found at such locations due to the presence of high traffic levels and traffic flow controls and intersections are more common than regular street canyons in real cities. Intersection flow and dispersion processes are extremely complex, making their treatment much more difficult than that found adequate for basic street canyons (see, e.g. Hoydysh and Dabberdt, 1994; Kastner-Klein et al., 1997; Wichmann-Fiebig et al., 1997; Scaperdas and Colvile, 1999; Robins et al., 2002).

Most existing urban dispersion models are not applicable to near field dispersion modelling at urban intersections and the development of a specialised intersection dispersion model has received only very limited attention. Yamartino and Wiegand (1986) briefly considered a simple methodology for including the effect of street canyon intersections, as part of the development of CPBM (Canyon Plume Box Model). The intersection was considered in terms of a well mixed reactor that is fed polluted air by one or more street canyons, and drained of pollutants by other neighbouring street canyon. A simple mass balance could then be used to calculate concentrations within the canyons, using CPBM. However, they did not have experimental data to evaluate this approach and recognised that "a realistic modelling of concentrations and their gradients within an intersection must involve three dimensional aspects of the flow", such as for example, "canyon edge vortices". Based on this concept, Scaperdas (2000) analysed an extensive experimental data-set (flow measurements in a wind tunnel) in order to quantify volume flux exchanges between the canyons at intersections of different shape and geometry. Unfortunately, tracer concentration measurements were not available at the same positions as the flow measurements and, therefore, pollutant mass fluxes could not be evaluated. These data were used, together with results from CFD (Computational Fluid Dynamics) simulations (Ketzel et al. 2002), to develop intersection parameterisations for the three dimensional street canyon model SEP-SCAM (Semi-Empirical Parameterised Street Canyon Model, Papathanassiou et al., 2008). More details of the previous literature in this field can be found in the paper by Belcher (2005), who reviewed several approaches to modelling flow and dispersion in urban areas, discussing, in particular, the role of street intersections.

Recently, a 'street network' modelling concept has been developed (Soulhac, 2000) for neighbourhood-scale dispersion. The basic concept is that a series of short streets form a network of boxes that comprise the canopy space. Tracer material is advected along the streets and is assumed to be well mixed within each box, due to vigorous mixing from recirculatory structures and locally generated turbulence around the obstacles. The transfers of tracer between streets, and between the canopy and the air above are parameterised on the basis of mass flux balances from wind tunnel experiments and CFD simulations (Hamlyn et al., 2007; Soulhac et al., 2008).

In the present work, tracer concentration measurements in a wind tunnel were carried out in order to describe the complex three-dimensional dispersion patterns occurring in a realistic urban environment. For this purpose, a 'Fast' Flame Ionisation Detector (FFID) was employed. This instrument is capable of measuring hydrocarbon concentration fluctuations. The study is the natural follow-up to a previous set of wind tunnel experiments (Carpentieri et al. 2009) that focussed on measuring the three-dimensional flow field at the canyon intersection by means of laser-Doppler anemometry (LDA) and flow visualisation (FV) techniques. The resulting data 
set, which combines the results of three sets of experiments (FV+LDA+FFID), is the most complete and, as flow and concentration have been measured at the same points, allowed us to estimate the mean pollutant flux balance at the intersection, particularly useful for model validation and model development purposes.

This study is part of the DAPPLE (Dispersion of Air Pollution and its Penetration into the Local Environment) series of projects. These began as a 4-year U.K. Engineering and Physical Sciences Research Council (EPSRC) funded project within the Engineering for Health, Infrastructure and Environment Programme (Arnold et al., 2004). The work then continued under a 3-year follow-up project (DAPPLE-HO) funded by the UK Home Office (Wood et al., 2009). A key objective of DAPPLE is to provide a better understanding of pollutant dispersion processes in realistic urban environments, such as a street canyon intersection studied here. DAPPLEs interdisciplinary approach aims to enhance understanding of the physical processes affecting the street and neighbourhood scale flow of air, traffic and people, by means of field measurements (meteorology, roadside pollution levels, traffic flow, personal exposure and inert tracer releases), wind tunnel modelling and computer simulations. General information about the project can be found at www.dapple.org.uk.

\section{Tracer concentration measurements}

\subsection{Wind tunnel model}

The DAPPLE site (see also Carpentieri et al., 2009) is located at the intersection between Marylebone Road and Gloucester Place in Central London, UK, with a surrounding study area approximately $250 \mathrm{~m}$ in radius. Wind tunnel modelling extends to a radius of about $500 \mathrm{~m}$. Marylebone Road is a busy dual carriageway (A501) and forms the northern boundary of the London Congestion-Charging Zone. Gloucester Place is 3 lanes, one-way northbound (Baker Street is southbound one block to the East). The roads intersect perpendicularly and Marylebone Road runs approximately from west-south-west to east-north-east. The prevailing wind is south-westerly, and the average building height is approximately $22 \mathrm{~m}$. As it is a real site, the heights and sizes of the buildings and streets are all different and this strongly influences the pollutant dispersion mechanism within the intersection.

The experiments were carried out at the boundary layer wind tunnel of the Environmental Flow Research Centre (EnFlo) at the University of Surrey, UK. It is an open circuit, 'suckdown' wind tunnel with a $20 \mathrm{~m}$ long, $3.5 \mathrm{~m}$ wide and $1.5 \mathrm{~m}$ high working section. The wind speed range is from 0.3 to $3.5 \mathrm{~m} \mathrm{~s}^{-1}$, and the facility is capable of simulating both stable and unstable atmospheric conditions, although these features were not used in this study. Reference flow conditions were measured by two ultrasonic anemometers, one held at a fixed location and the other positioned as required, and two propeller anemometers mounted on either side of the traverse carriage. The motor shaft speed was also measured. Temperature conditions were monitored by thermocouple rakes in the flow and individual thermocouples in each tunnel wall panel. The pressure drop across the inlet was also monitored, primarily to indicate the state of the inlet screens. The wind tunnel and the associated instrumentation are fully automated and controlled using 'virtual instrument' software created in LabVIEW by EnFlo research staff.

The 1:200 model installed in the wind tunnel is the simplest DAPPLE site model, where all buildings have been reduced to simple blocks with flat roofs. The generated boundary layer has a thickness of $\approx 1 \mathrm{~m}$ and a surface roughness $z_{0}=1.5 \mathrm{~mm}$ (equivalent to $0.3 \mathrm{~m}$ at full scale). 
Most of the tests were carried out with a reference wind speed $\left(U_{r e f}\right)$ of about $2.5 \mathrm{~m} \mathrm{~s}^{-1} . U_{r e f}$ was measured with an ultrasonic anemometer positioned outside the boundary layer.

A site-aligned co-ordinate system was used, with the $x$ axis along Marylebone Road, positive towards the east, and the $y$ axis along Gloucester Place, positive towards the north. Wind vector directions were defined as zero along the positive $x$-axis and positive anticlockwise. The model was mounted on a turntable and aligned to give a wind direction of $51.4^{\circ}$, as in the first field tracer dispersion experiment (Arnold et al. 2004). This corresponds to a wind approximately from the south-west.

\subsection{Tracer dispersion experiments}

Tracer concentration measurements were carried out to investigate the dispersion phenomena within the intersection. Dispersion experiments were performed by releasing a neutrally buoyant gas 'tracer' into the flow and measuring its concentration using air sampling at selected points downstream. The tracer used was a gas mixture of (order 1\%) ethylene (or propane, in a second series of experiments) in air, the precise source concentration chosen to optimise detectability. To approximate a passive, ground level point source, the tracer gas was released vertically downwards from a pipe positioned at a small distance above the surface, with very low initial momentum.

The instrument used for concentration measurement was a CAMBUSTION FFID, a fast response instrument that is capable of measuring hydrocarbon concentration fluctuations with a frequency response of about $200 \mathrm{~s}^{-1}$. The average sampling time was generally set to about 1 minute, as in previous LDA experiments (Carpentieri et al., 2009), though some measurements were performed using a longer averaging time.

Eight different source locations were used, all at a height of $\mathrm{z}=10 \mathrm{~mm}$; five were in Marylebone Road and three in Gloucester Place, as shown in Figure 1. Multiple point sources were used so that the combined concentration fields filled the lateral extent of the street canyon in which they were located. The location of the sources allowed us to investigate the problem from a 'near-to-intermediate field' perspective (see, e.g., Belcher, 2005; Wood et al., 2009, for a description of the classifications: near-, intermediate-, and far-field).

The measurement points were on the 6 levels chosen for the previous LDA experiments ( $\mathrm{z}$ $=25,50,75,100,125$ and $150 \mathrm{~mm}$ ), with an additional level at $10 \mathrm{~mm}$ from the ground. A regular $40 \mathrm{~mm}$ x $40 \mathrm{~mm}$ horizontal measurement grid was used, so that concentration values were available at the same locations as the LDA flow measurements (Carpentieri et al., 2009, see also Figure 2).

Of course, this set of sources were effectively at ground level and the resulting plumes by no means fill the street canyons in which the sources were located. Other configurations were possible but the set-up investigated is relevant to air quality modelling as emissions at and near intersections tend to be much greater than those further away because of the time spent queuing and the deceleration/acceleration driving behaviour at intersections. Air fluxes can, of course, also be derived directly from the velocity field data but linking any given exit flow with an inlet flow requires tracer to be added. 


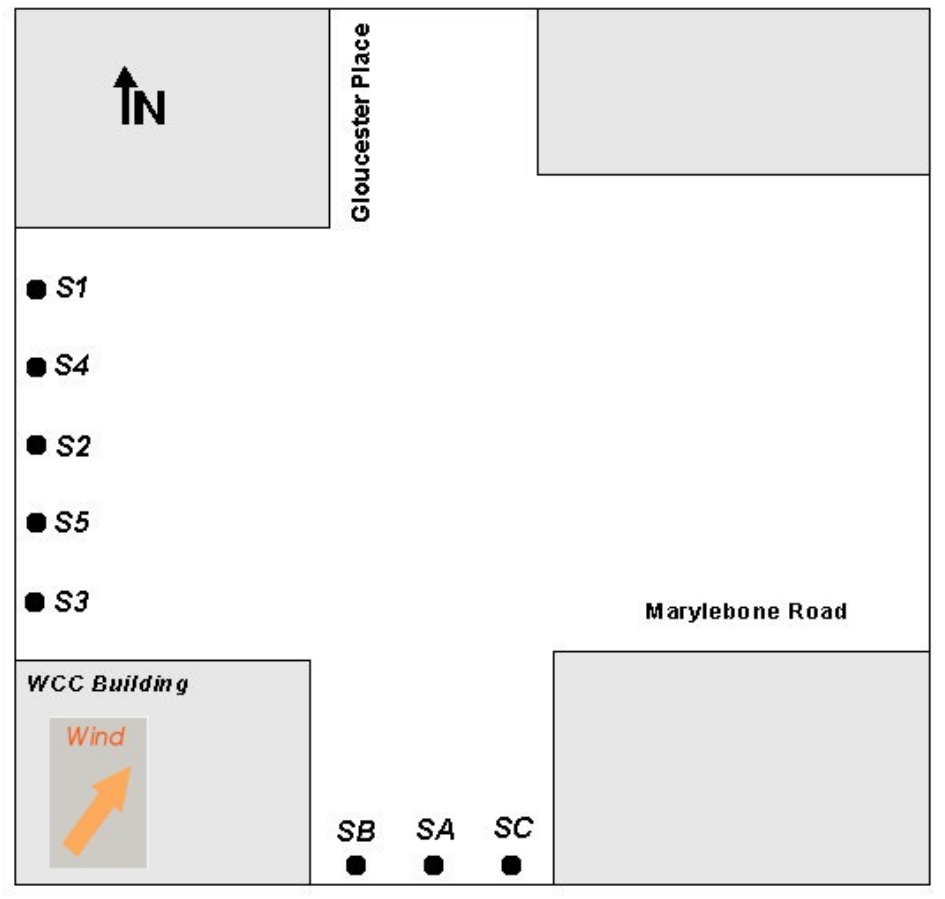

Figure 1: Source locations for the tracer concentration measurements

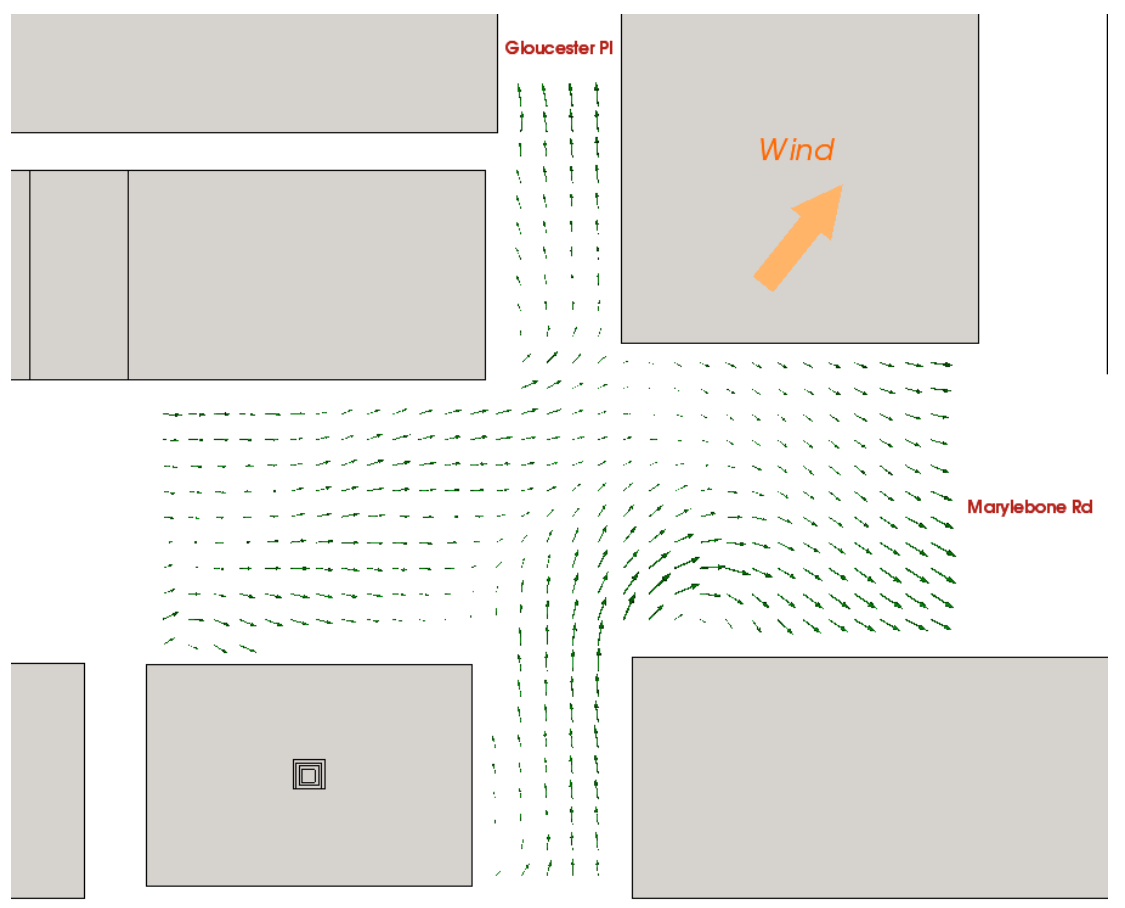

Figure 2: Horizontal velocity field at $z=25 \mathrm{~mm}$ derived from LDA measurements Carpentieri et al. 2009) 


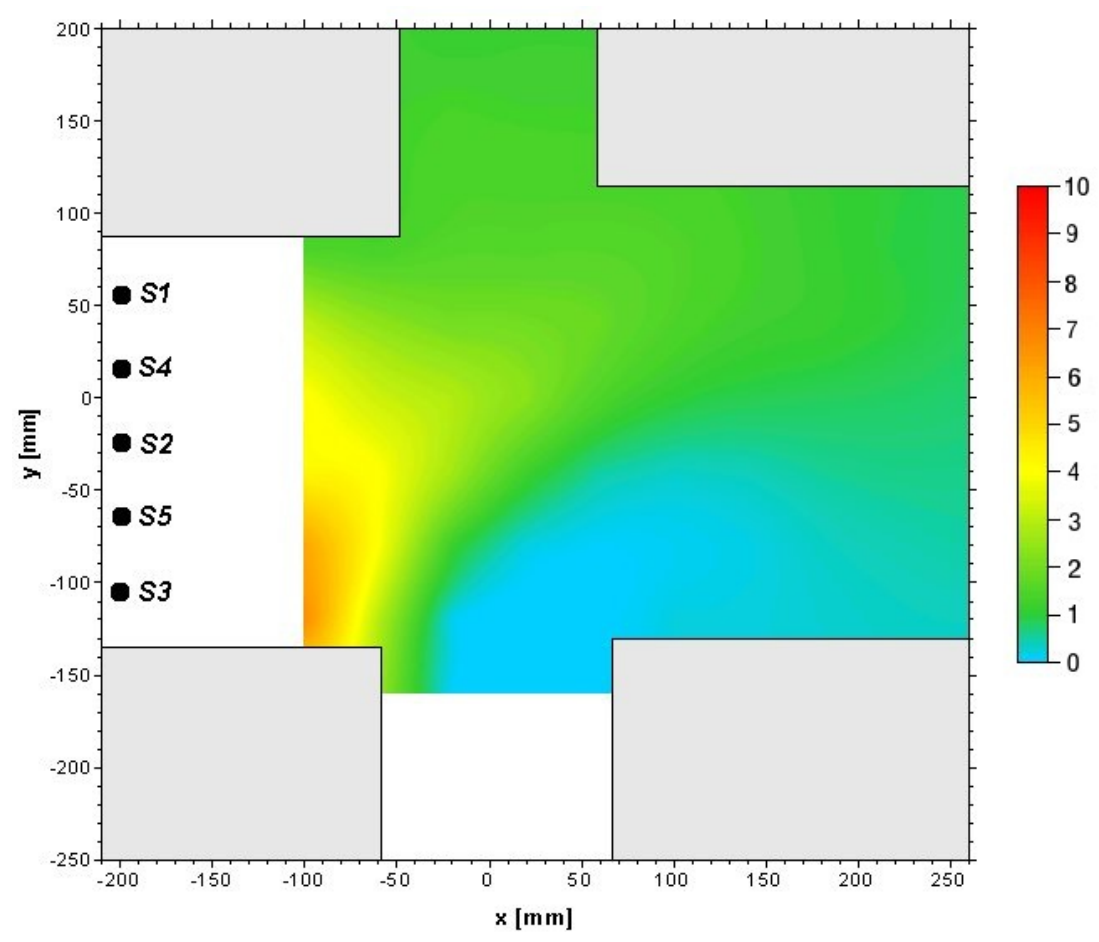

Figure 3: Non-dimensional concentrations at $z=10 \mathrm{~mm}$, source height $10 \mathrm{~mm}$; all the Marylebone Road sources

\subsection{Results}

Results are reported in terms of the non-dimensional concentration and velocity, $C^{*}$ and $U^{*}$ :

$$
\begin{gathered}
C^{*}=\frac{C U_{r e f} H_{r e f}^{2}}{Q} \\
U^{*}=\frac{U}{U_{r e f}}
\end{gathered}
$$

where $C$ and $U$ are the measured mean volume concentration and air speed, $U_{r e f}$ the reference wind speed at the boundary layer edge, $H_{r e f}$ a reference length (in this case the average building height of the model, $110 \mathrm{~mm}$ ) and $Q$ the volume emission rate. Example maps of the mean, ground level, non-dimensional concentration field are given in Figures 3, 4 and 5. These measurements were obtained at a height of $10 \mathrm{~mm}$, that is $2 \mathrm{~m}$ at full scale. The concentration maps for more than one source have been obtained by simple superposition of the maps for single sources.

As expected, the results show that the ground level concentration field was heavily influenced by the complex three-dimensional flow described by the flow visualisation and LDA experiments (Carpentieri et al., 2009). The circulation in the street canyons resulted in higher concentrations of tracer at ground level occurring on the leeward side of the streets, and thus at the south-west corner of the intersection due from the sum of the effects of the two canyons. In this situation, horizontal vortices observed by Carpentieri et al. (2009) resulted in a further increase in the concentrations at the south-west and north-west corners of the intersection, and a 'cleaner' area at the south-east corner. 


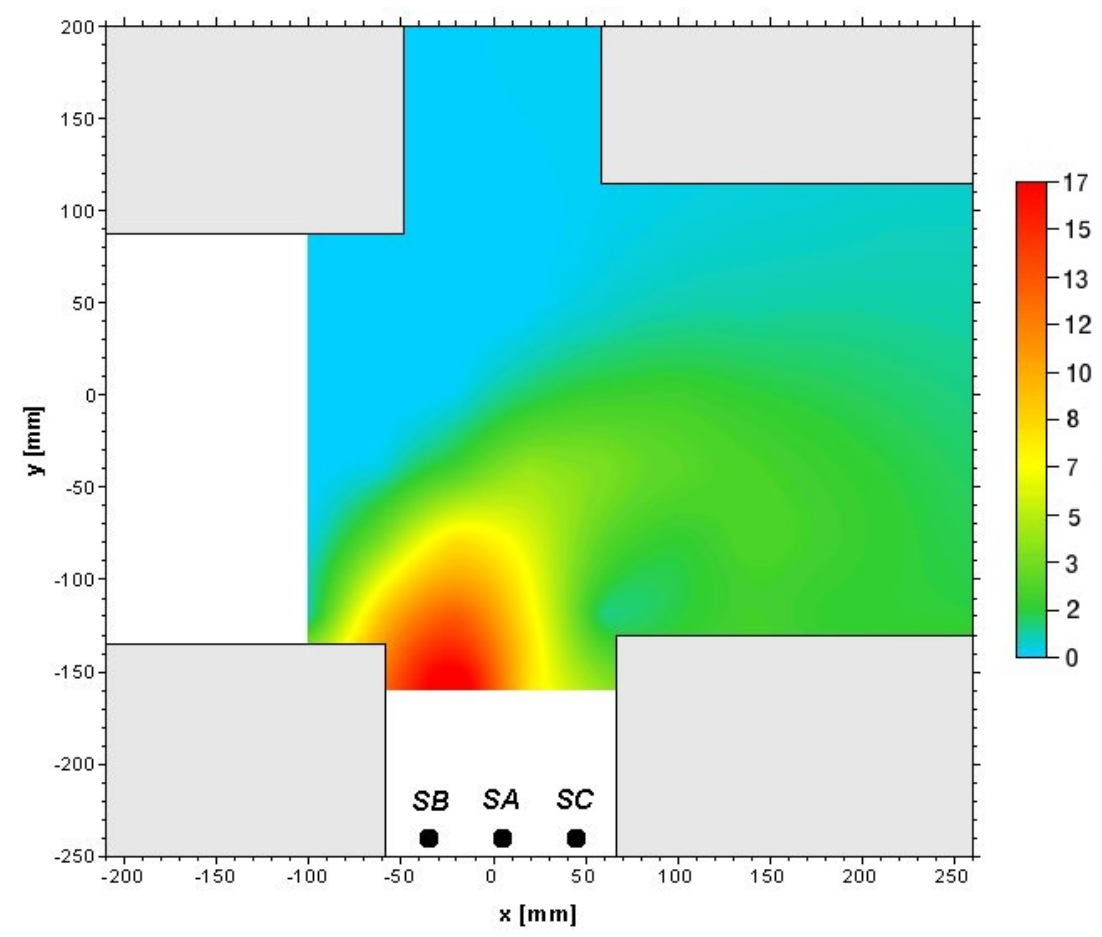

Figure 4: Non-dimensional concentrations at $z=10 \mathrm{~mm}$, source height $10 \mathrm{~mm}$; all the Gloucester Place sources

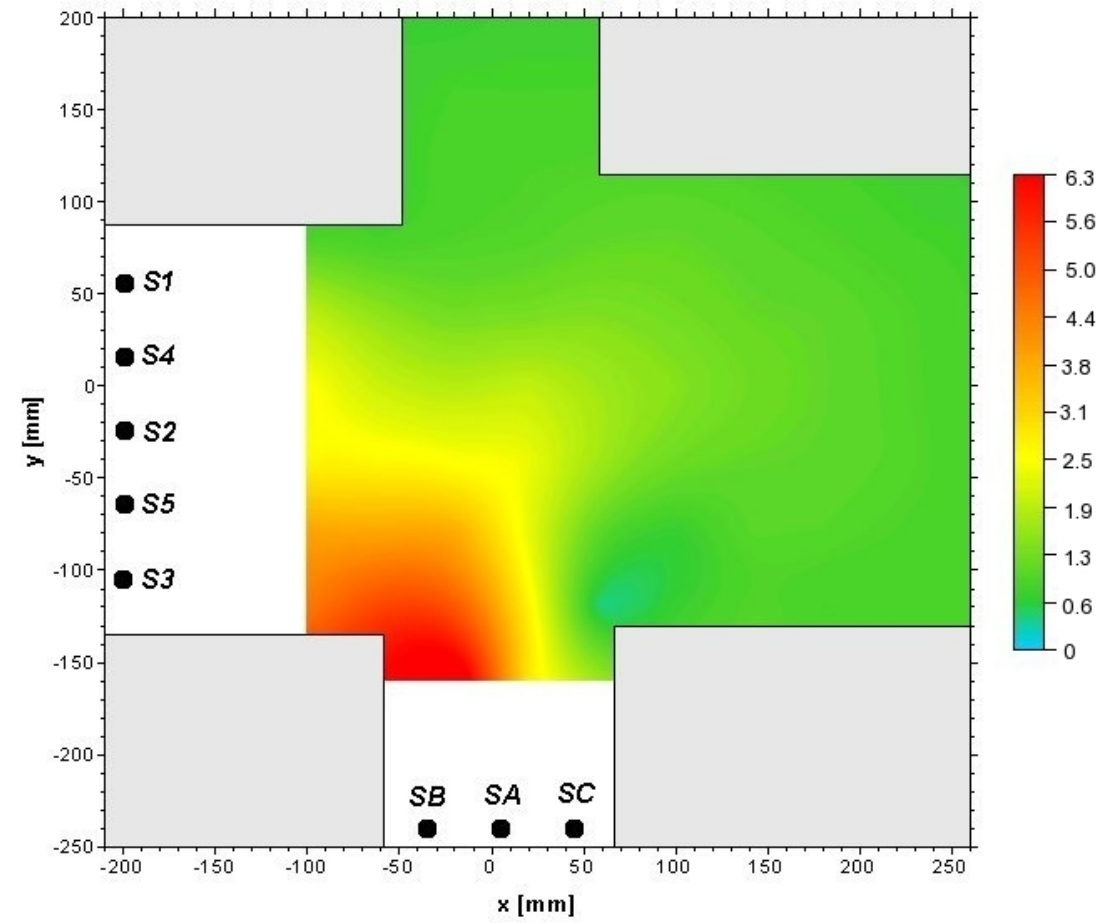

Figure 5: Non-dimensional concentrations at $z=10 \mathrm{~mm}$, source height $10 \mathrm{~mm}$; all the sources 


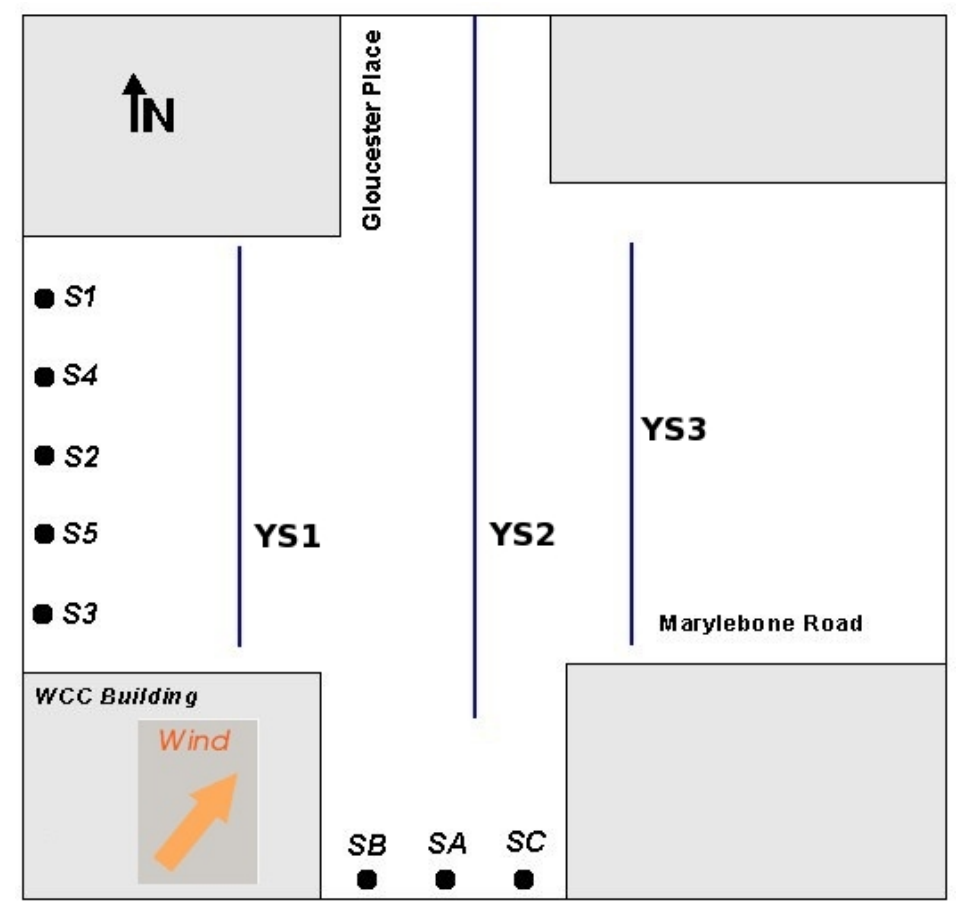

Figure 6: Vertical $y-z$ sections $(x=-100,20$ and $100 \mathrm{~mm}$ ) showed in the following figures

At ground level, it can be observed from Figure 4 that nearly all the incoming tracer from Gloucester Place was, on average, deflected into the main stream in Marylebone Road, while the incoming tracer from Marylebone Road was carried either into one canyon or the other (Figure 3), depending on its initial position and the state of the unsteady 'switching' vortices observed by Carpentieri et al. (2009). Concentration maps in three vertical $y$ - $z$ sections, defined by Figure 6, are shown in Figures $7-8$.

Despite the asymmetrical geometry, the tracer from these sources tended to remain mostly within the canyons, with only limited exchange with the flow above roof level. Tracer transport near the centre of the intersection was very complex (Carpentieri et al., 2009). The incoming flow from Gloucester place was initially deflected downwards and then, near the centre of the intersection, spread vertically. Beyond the intersection centre, it was deflected again but this time upwards, by the incoming flow from Marylebone Road.

Vertical sections along the $x$ axis (not included in the figures) confirmed the observations of the $y-z$ sections. In particular, the trapping effect due to the recirculation vortices inside the canyons was clearly visible. This effect was weaker at the intersection centre, where a rapid vertical spread can be seen (see also Figure 8). The maximum exchange rate between the urban canopy and the above boundary layer above roof level is expected at this very location.

\section{Tracer flux balance}

Since most of the LDA measurements in Carpentieri et al. (2009) were made at the same positions as the FFID measurements presented in this paper, a pollutant flux balance at the intersection can be attempted. The methodology applied here is different from that in previous studies (Scaperdas, 2000, Robins et al., 2002) because both velocity and concentration measurements 


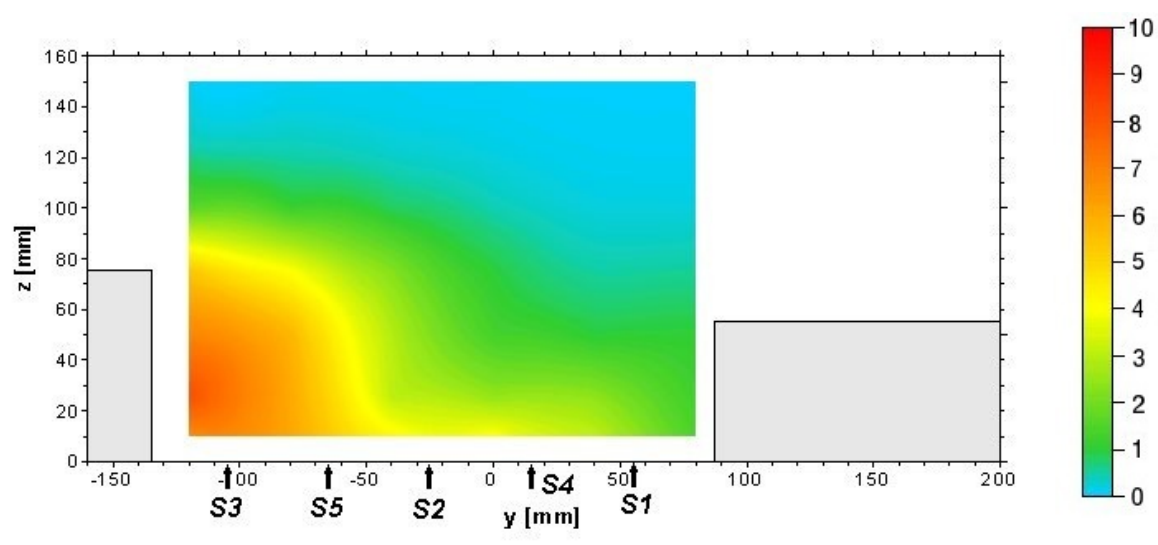

(a)

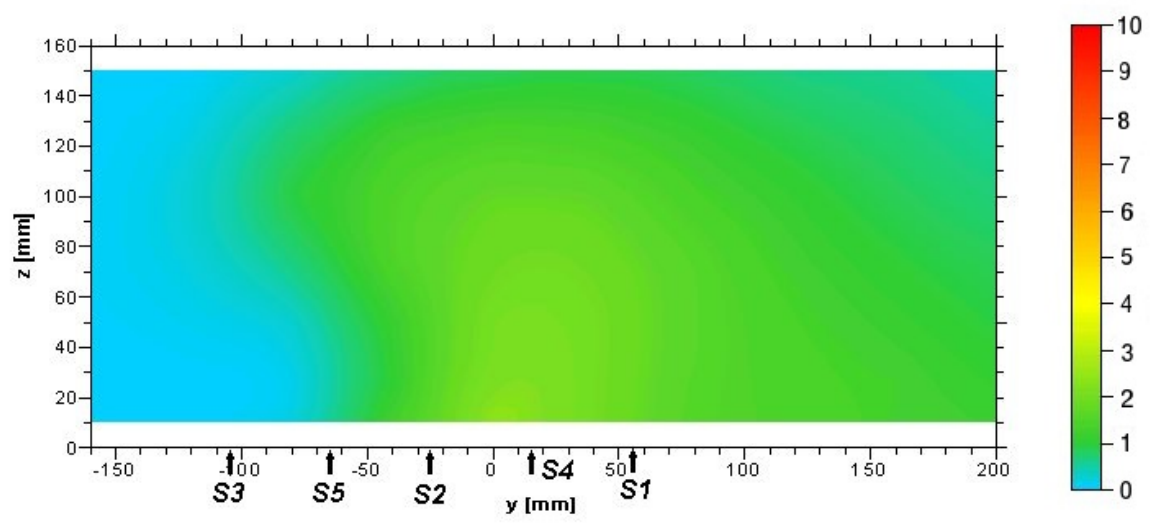

(b)

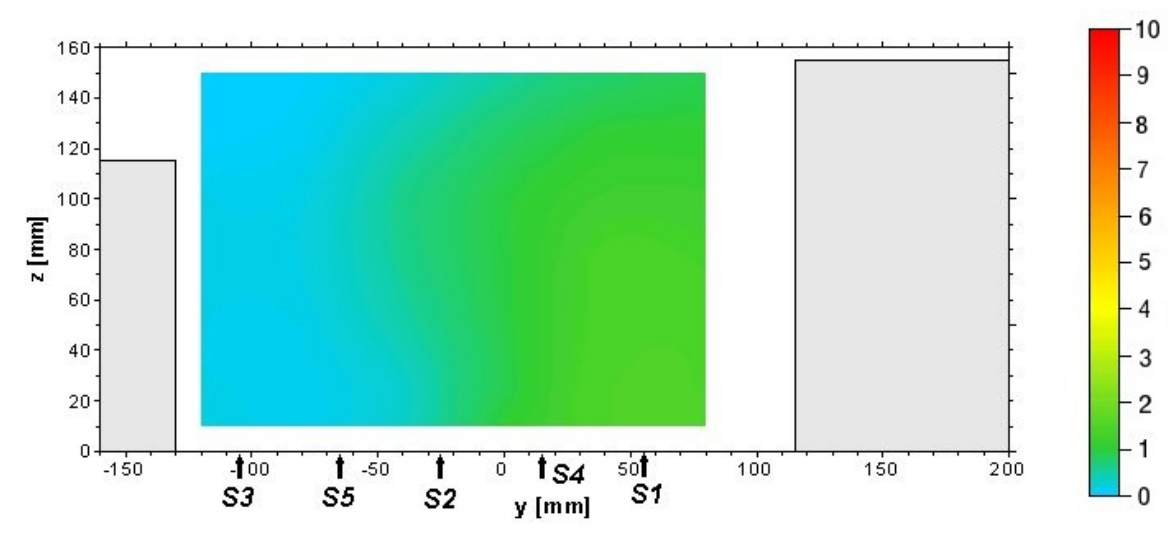

(c)

Figure 7: Non-dimensional concentrations at (a) $x=-100 \mathrm{~mm}$ (YS1), (b) $x=20 \mathrm{~mm}$ (YS2), and (c) $x=100 \mathrm{~mm}$ (YS3); sources in Marylebone Road, height $10 \mathrm{~mm}$ 


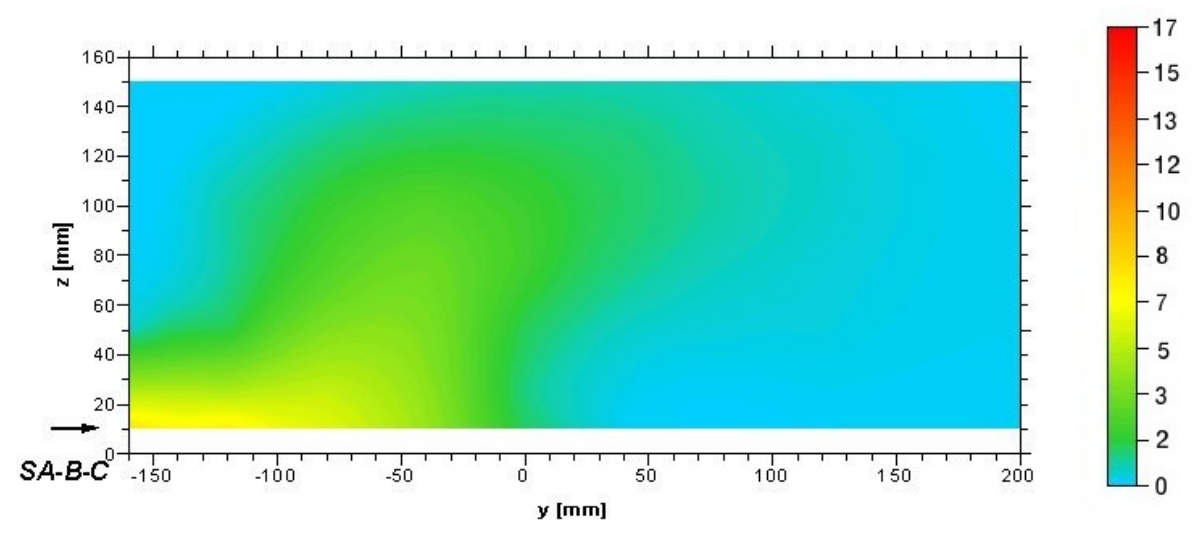

(a)

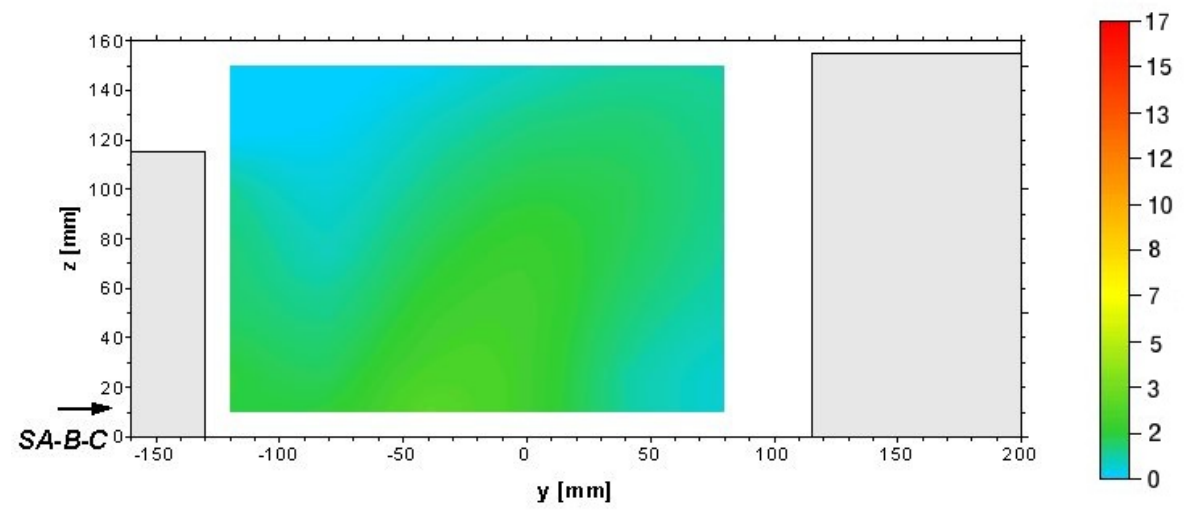

(b)

Figure 8: Non-dimensional concentrations at (a) $x=20 \mathrm{~mm}(\mathrm{YS} 2)$ and (b) $x=100 \mathrm{~mm}$ (YS3); sources in Gloucester Place, height $10 \mathrm{~mm}$ 
have been used and thus the tracer flux exchange between the streets can be estimated as well as the overall volume exchange.

The volume flux through a reference plane, as calculated by Scaperdas (2000) and Robins et al. (2002), can be simply estimated from the expression:

$$
\phi_{V}=\iint_{S} U_{n} d s
$$

where $S$ denotes the area of the plane, $s$ an element of area, and $U_{n}$ the mean flow normal to the plane. These volume flux values have been compared with the tracer volume fluxes derived from the joint concentration and velocity field data. Only the transport by the mean flow could be derived as simultaneous concentration and velocity measurements were not available. Overall, the tracer volume flux, $\phi_{M}$, through a reference plane $S$ is given by:

$$
\phi_{M}=\iint_{S}\left(U_{n} C+\left\langle u_{n} c\right\rangle\right) d s
$$

where $\left\langle u_{n} c\right\rangle$ is the mean turbulence flux across the plane. In the case studied here, where advection was strong along all streets (because of the wind direction was approximately at 045 degrees to the streets), we expect that turbulent fluxes, at least in the horizontal directions, were small in comparison with the advective transport. However, later work will address the turbulent fluxes directly and will be reported separately.

Four vertical sections (see Figures 9 and 10 ) were selected for the calculation, two upwind and two downwind the intersection, as well as the top horizontal section (at $150 \mathrm{~mm}$ ). The tracer volume flux through a specified 'cell' in a section has been calculated as the average of the fluxes at the corner points, $\phi_{M}=\frac{1}{4} \sum_{i} \phi_{M, i} A$, where $\phi_{M, i}=C_{i}^{*} U_{i}^{*}$ is the flux at each point $(i=1 . .4), C_{i}^{*}$ is the non dimensional concentration (equation 1$), U_{i}^{*}$ is the non dimensional velocity component perpendicular to the section plane (equation 2$), A$ is the area of the cell $\left(U_{i}^{*}\right.$ at any wall and at ground level was set to 0 ).

The grid spacing (mostly $40 \mathrm{~mm}$ horizontal and $25 \mathrm{~mm}$ vertical) did not really allow a very accurate estimate to be made of the flux in the incoming flows, particularly that from Gloucester Place. In effect, the measurement points proved to be insufficiently close to the walls and ground level and, thus, the flux profiles in these regions were not very well represented by the assumed linear variation across cells. The calculation of the fluxes in the outgoing flows was not affected by these problems because the concentration profiles were deeper and more uniform at the downwind sections. The flux balances were therefore expressed with respect to the total outgoing fluxes. These were smaller than the total emissions from the sources because not all of the emitted material reached the intersection. For example, the building in Marylebone Road on the north-west side of the junction is relatively low and a significant fraction of the emissions in Marylebone Road were lost from the street canyon and carried over the roof of this building.

The results (see Figure 97 from the tracer flux balance at the intersection show that about $47 \%$ of the incoming pollutant from Marylebone Road (calculated as percentage of the total outgoing flux) continues in that street, while about $50 \%$ deviates into Gloucester Place (north) and $3 \%$ is lost through the top section. On the other hand, most of the tracer coming from Gloucester Place is entrained into Marylebone Road (85\%), with only $13 \%$ continuing along Gloucester Place (North) and 2\% lost to the above roof flow.

The tracer flux balance calculation substantially confirms the qualitative observations from the flow visualisation experiments by Carpentieri et al. (2009). 


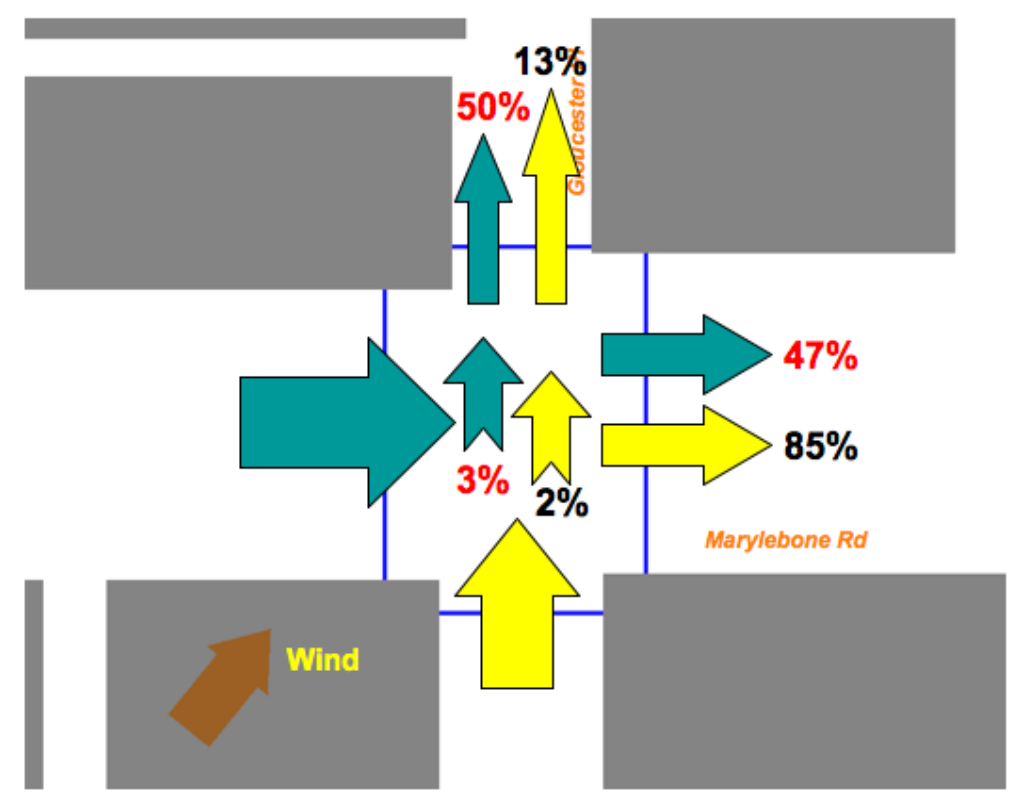

Figure 9: Tracer volume flux balance expressed in terms of the total outgoing flux

The average tracer fluxes through the top section (and thus, supposedly, the exchange between the canopy and the above layer) were quite limited, accounting for just $2.5 \%$ of the total emitted tracer. The estimation of this flux was, however, rather imprecise. The buildings surrounding the intersection have very different heights, ranging from $55 \mathrm{~mm}$ (about $11 \mathrm{~m}$ at full scale) for Marathon House (on the north-west side of the intersection), to $155 \mathrm{~mm}$ (about 31 $\mathrm{m}$ at full scale) for the building on the north-east side. The choice of an appropriate 'upper' boundary was therefore quite difficult. The $150 \mathrm{~mm}$ level was chosen, given the importance of the downwind building on the vertical exchange within the intersection. In this case, we could rely on the fact that most of the tracer below that level remained within the canyons beyond the intersection (at least until the end of the $155 \mathrm{~mm}$ tall block), while the tracer passing through the upper boundary is probably entrained into the canopy flow above. If the building arrangement were different then the situation might have been even more complex. Another uncertainty in the estimate of the vertical flux lies in the fact that much of the exchange mechanism here was probably a turbulent process, while in the analysis only the advective terms were considered (and it was not be possible to do otherwise, given the fact that velocity and concentration measurements had been taken at different times).

The percentages of the outgoing fluxes have been calculated in terms of the total outgoing flux. An imbalance of about $6 \%$ between the incoming and outgoing fluxes was found and this might be caused by several factors:

- measurement errors;

- high concentration gradients at the in-flow sections, which, in combination with the spatial resolution of the measurements, resulted in significant numerical error and undetected fluxes near the walls and the ground; and

- turbulent fluxes that have been ignored, which could result in significant error where the mean velocity normal to the plane was small, (especially for the fluxes between the 
canopy and the flow above roof level) and where concentrations fluctuation were relatively large (e.g., as observed in the south-west corner of the intersection, Carpentieri et al. 2009).

These possible sources of error can introduce either a positive or a negative error into the calculations and, thus, the $6 \%$ value quoted above (simply as the difference between the incoming and outgoing fluxes) is by no means a maximum limit for the sum of the errors. It is not clear how this will affect the reliability of the estimates. Clearly, care should be exercised when estimating the flux through the top section by simple difference between the incoming and the outgoing fluxes, as the result might be contaminated by any or all of the above errors. The next logical step in this research, though by no means a trivial one, is to measure the turbulent tracer fluxes directly and the results of this effort will be reported in due course.

For comparison purposes, volume fluxes have been estimated by using LDA data only, following the methodology proposed by Scaperdas (2000) and Robins et al. (2002), except that, unlike in the original applications, in this case the vertical fluxes through the top section have been measured rather than derived from imbalance in the other fluxes. The results of the volume flux estimates are shown in Figure 10 as percentage of the incoming fluxes. For an easy comparison, the results of the tracer flux calculations have also been included in Figure 10 as percentages of the incoming fluxes, without source apportionment.

The volume flow in Gloucester Place shown in Figure 10 is surprisingly large compared with that in Marylebone Road, given that the cross sectional area of Gloucester Place is considerably smaller that that of Marylebone Road and that the components of the wind above roof level parallel to the respective streets only differ by about $20 \%$. The volume flux results show that the flow along Marylebone Road increased by about $40 \%$ across the intersection and that in Gloucester Place reduced to compensate. The pollutant flux exchanges followed this pattern, with the flux in Marylebone Road increasing significantly across the intersection. This suggests that knowledge of the volume flux balance, which on the whole is easier to measure, can give a reasonable estimate of the pollutant exchanges. However, it is only measurement of the pollutant fluxes that can assign the contributions to the outgoing fluxes from the original sources, so both types of measurement are clearly valuable.

\section{Conclusions}

This paper presents results from tracer concentration measurements that were carried out in a wind tunnel in order to describe the complex three-dimensional dispersion patterns occurring in a realistic urban environment, in particular at a busy street intersection in central London. Fast flame ionisation detector measurements were employed to derive three-dimensional maps of the concentration field at the intersection.

As highlighted by previous studies (Carpentieri et al., 2009), the flow field within the intersection was very complex and highly three-dimensional, and this naturally resulted in complex concentration fields. The circulations within the street canyons caused higher ground level concentrations of tracer to occur on the leeward side of the streets. The simple model proposed by Soulhac (2000) for street intersections, which assumes a complete mixing in the intersection, does not seem to be adequate for intersections with complex geometry, like the one studied here. This fact is also supported by studies that have analysed less complex intersections (Soulhac 

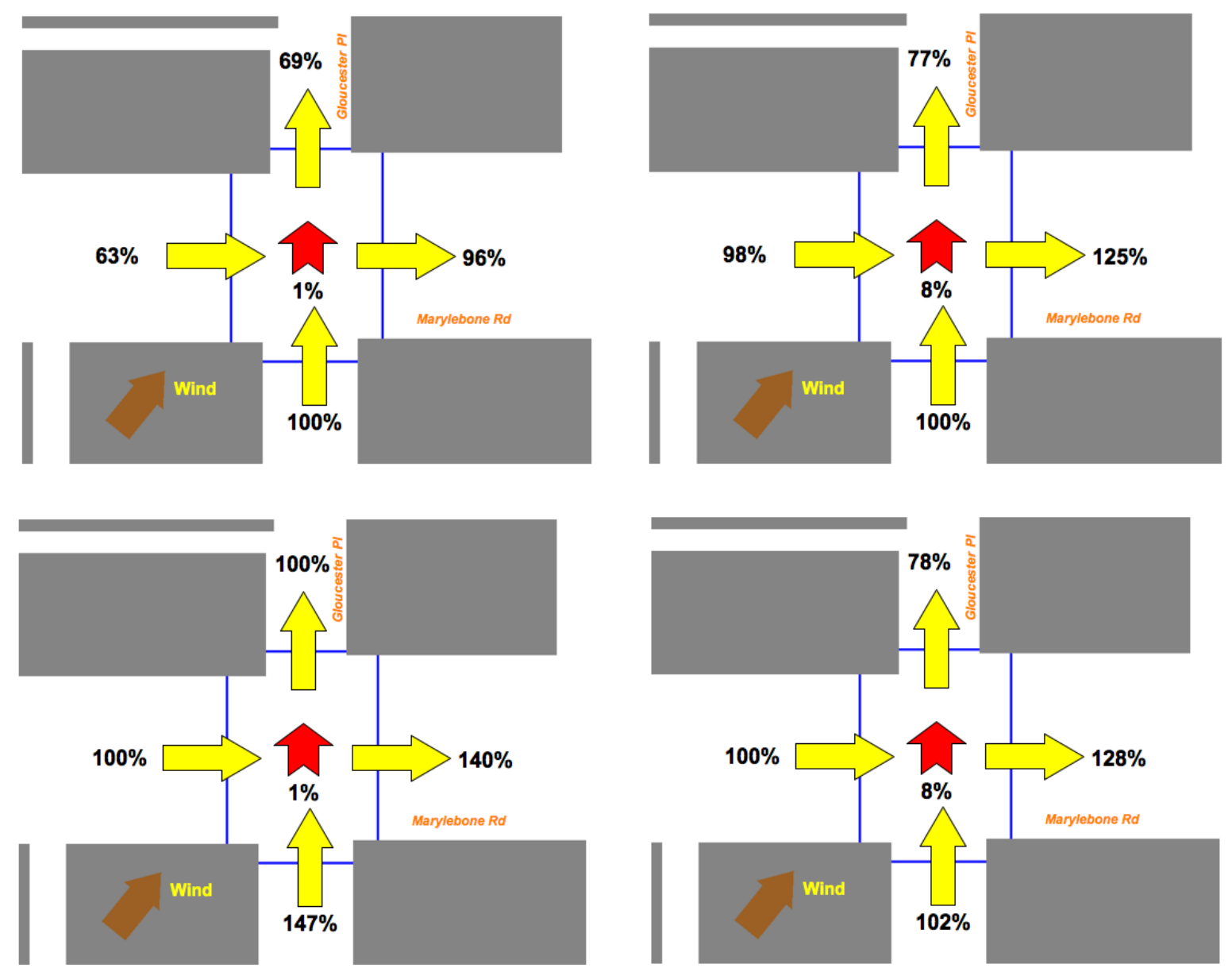

Figure 10: Volume (left) and tracer (right) exchange balance expressed in terms of the incoming flux from Gloucester Place (top) and from Marylebone Road (bottom) 
et al., 2009). Of course, the sources studied were effectively at ground level, near the intersection and a different picture would emerge if they were distributed throughout the canyon. However, we argue that the case studied is most pertinent to air quality applications because of the likelihood of relatively high emission rates from vehicles in the vicinity of intersections.

The tracer concentration measurements were located where previous flow measurements (Carpentieri et al., 2009) were also available. This allowed a tracer flux balance to be calculated at the intersection. The proposed methodology was based on the calculation of the average tracer fluxes through the four vertical sections constituting the interface between the street canyons and the intersection. The mean flux through the top horizontal section was also estimated. One important result from this was the magnitude of the mean flux observed between the southern and the northern sections of Gloucester Place. Given the wind direction and the intersection geometry, one might have expected all the tracer emitted in that street to be entrained into the wider Marylebone Road. On the contrary, flow instabilities and threedimensional effects within the intersection (see also Carpentieri et al., 2009) resulted in about $13 \%$ of the incoming mean flux from Gloucester Place continuing along that street, north of the intersection. This feature is not necessarily observed in more regular street canyon intersections (Soulhac et al., 2009) and should be taken into account by street intersection dispersion models. Many regulatory models neglect any interactions of the type found here and simply add the contributions from the two streets forming the intersection, thus neglecting the $85 \%$ of the flux from Gloucester Place that transfers into Marylebone Road (east) and the $50 \%$ of the flux from Marylebone Road into Gloucester Place (north) and, therefore, failing to provide a realistic prediction of concentration levels.

The methodology proposed in this paper, to our knowledge, is the first attempt to derive tracer flux balance calculations in a realistic environment. However, the procedure as applied has a number of limitations and should be improved before further application in model development and evaluation work. The spatial resolution of the measurements, for example, did not allow a reliable estimation to be made of the incoming fluxes. Furthermore, it is not clear how inclusion of the turbulent fluxes will affect the overall tracer flux balance of the intersection. In order to estimate turbulent fluxes, velocity and concentration measurements have to be taken simultaneously and this is the subject of the continuing research effort. The results reported in this paper are, obviously, very case-specific and strongly dependent on the particular geometry of the site and the choice of the (single) wind direction. A generalisation of the findings by using simpler, but still realistic models and different wind directions is also an ongoing field of investigation in the EnFlo laboratory.

\section{Acknowledgements}

The DAPPLE project has been funded by the Engineering and Physical Sciences Research Council (EPSRC). The experimental work was carried out in the EnFlo Laboratory by Matteo Carpentieri during his $\mathrm{PhD}$ research funded by the University of Florence.

\section{References}

Arnold SJ, ApSimon H, Barlow J, Belcher S, Bell M, Boddy JW, Britter R, Cheng H, Clark R, Colvile RN, Dimitroulopoulou S, Dobre A, Greally B, Kaur S, Knights A, Lawton T, 
Makepeace A, Martin D, Neophytou M, Neville S, Nieuwenhuijsen M, Nickless G, Price C, Robins A, Shallcross D, Simmonds P, Smalley RJ, Tate J, Tomlin AS, Wang H, Walsh P (2004) Introduction to the DAPPLE air pollution project. Sci Total Environ, 332:139-153

Belcher SE, (2005) Mixing and transport in urban areas. Philos T Roy Soc A, 363:2947-2968

Berkowicz R, Palmgren F, Hertel O, Vignati E (1996) Using measurements of air pollution in streets for evaluation of urban air quality - meteorological analysis and model calculations. Sci Total Environ, 189-190:259-265

Berkowicz R, Hertel O, Larsen SE, Sørensen NN, Nielsen M (1997) Modelling traffic pollution in streets. Danish Ministry of Environment and Energy, National Environmental Research Institute

Britter RE, Hanna SR (2003) Flow and dispersion in urban areas. Annu Rev Fluid Mech, 35:469-496

Buckland AT (1998) Validation of a street canyon model in two cities. Environ Monit Assess, 52:255-267

Carpentieri M, Robins AG, Baldi S (2009) Three-dimensional mapping of air flow at an urban canyon intersection. Boundary-Layer Meteorol, 133:277-296

Fenger J (1999) Urban air quality. Atmos Environ, 33:4877-4900

Hamlyn D, Hilderman T, Britter RE (2007) A simple network approach to modelling dispersion among large groups of obstacles. Atmos Environ, 28:5848-5862

Hoydysh WG, Dabberdt WF (1994) Concentration fields at urban intersections: fluid modeling studies. Atmos Environ, 28:1849-1860

Hoydysh WG, Griffiths RA, Ogawa Y (1974) A scale model study of the dispersion of pollutants in street canyons. Paper 1974-157, Proc. $67^{\text {th }}$ Annual Meeting of the Air Pollution Control Association, Denver, Colorado, 9-13 June, 24 pp

Johnson WB, Ludwig FL, Dabberdt WF, Allen RJ An urban diffusion simulation model for carbon monoxide. JAPCA J Air Waste Ma, 23:490-498

Kastner-Klein P, Plate EJ, Fedorovich E (1997) Gaseous pollutant dispersion around urban canopy elements: wind tunnel case studies. Int J Environ Pollut, 8:727-737

Ketzel M, Louka P, Sahm P, Guilloteau E, Sini J-F, Moussiopoulos N (2002) Intercomparison of numerical urban dispersion models - Part II: Street canyon in Hannover, Germany. Water Air Soil Pollut Focus, 2:603-613

Papathanassiou A, Douros I, Moussiopoulos N (2008) A simplified three-dimensional approach to street canyon modelling using SEP-SCAM. Environ Modell Softw, 23:304-313

Robins A, Savory E, Scaperdas A, Grigoriadis D (2002) Spatial variability and source-receptor relations at a street intersection. Water Air Soil Pollut Focus, 2:381-393 
Scaperdas A, Colvile RN (1999) Assessing the representativeness of monitoring data from an urban intersection site in central London, UK. Atmos Environ, 33:661-674

Scaperdas A-S (2000) Modelling flow and pollutant dispersion at urban canyon intersections. $\mathrm{PhD}$ thesis, Imperial College of Science, Technology and Medicine, University of London

Soulhac L (2000) Modélisation de la dispersion atmosphérique á l'intérieur de la canopée urbaine. PhD thesis, École Centrale de Lyon, France

Soulhac L, Perkins RP, Salizzoni P (2008) Flow in a street canyon for any external wind direction. Boundary-Layer Meteorol, 126:365-388

Soulhac L, Garbero V, Salizzoni P, Mejean P, Perkins RP (2009) Flow and dispersion in street intersections. Atmos Environ, in press, DOI 10.1016/j.atmosenv.2009.02.061

Vardoulakis S, Fisher BEA, Pericleous K, Gonzalez-Flesca N (2003) Modelling air quality in street canyons: a review. Atmos Environ, 37:155-182

Wichmann-Fiebig M, Pfeffer H-U, Rau M (1997) A dataset for the validation of flow and dispersion models as an urban intersection. Int J Environ Pollut, 8:747-760

Wood CR, Arnold SJ, Balogun AA, Barlow JF, Belcher S, Britter RE, Cheng H, Dobre A, Lingard JJN, Martin D, Neophytou MK, Petersson FK, Robins AG, Shallcross DE, Smalley RJ, Tate JE, Tomlin AS, White IR (2009) Dispersion experiments in Central London: the 2007 DAPPLE project. Bull Am Meteorol Soc, 90:955-969

Yamartino RJ, Wiegand G (1986) Development and evaluation of simple models for the flow, turbulence and pollutant concentration fields within an urban street canyon. Atmos Environ, 20:2137-2156 